University of Nebraska - Lincoln

DigitalCommons@University of Nebraska - Lincoln

2008

\title{
Trends in Twentieth-Century U.S. Snowfall Using a Quality- Controlled Dataset
}

\author{
Kenneth E. Kunkel \\ University of Illinois at Urbana-Champaign, kkunkel@uiuc.edu \\ Michael Palecki \\ University of Illinois at Urbana-Champaign \\ Leslie Ensor \\ University of Illinois at Urbana-Champaign \\ Kenneth Hubbard \\ University of Nebraska - Lincoln, khubbard1@unl.edu \\ David Robinson \\ The State University of New Jersey, Piscataway
}

See next page for additional authors

Follow this and additional works at: https://digitalcommons.unl.edu/natrespapers

Part of the Natural Resources and Conservation Commons, Natural Resources Management and Policy Commons, and the Other Environmental Sciences Commons

Kunkel, Kenneth E.; Palecki, Michael; Ensor, Leslie; Hubbard, Kenneth; Robinson, David; Redmond, Kelly; and Easterling, David, "Trends in Twentieth-Century U.S. Snowfall Using a Quality-Controlled Dataset" (2008). Papers in Natural Resources. 1240.

https://digitalcommons.unl.edu/natrespapers/1240

This Article is brought to you for free and open access by the Natural Resources, School of at DigitalCommons@University of Nebraska - Lincoln. It has been accepted for inclusion in Papers in Natural Resources by an authorized administrator of DigitalCommons@University of Nebraska - Lincoln. 
Authors

Kenneth E. Kunkel, Michael Palecki, Leslie Ensor, Kenneth Hubbard, David Robinson, Kelly Redmond, and David Easterling 


\title{
Trends in Twentieth-Century U.S. Snowfall Using a Quality-Controlled Dataset
}

\author{
Kenneth E. Kunkel, Michael PAlecki, And Leslie Ensor \\ Illinois State Water Survey, University of Illinois at Urbana-Champaign, Champaign, Illinois \\ KENNETH G. HuBBARD \\ University of Nebraska-Lincoln, Lincoln, Nebraska \\ DAVID ROBINSON \\ Rutgers, The State University of New Jersey, Piscataway, New Jersey \\ KELLY REDMOND \\ Desert Research Institute, Reno, Nevada \\ DAVID EASTERLING \\ National Climatic Data Center, Asheville, North Carolina
}

(Manuscript received 11 March 2008, in final form 13 June 2008)

\begin{abstract}
A quality assessment of daily manual snowfall data has been undertaken for all U.S. long-term stations and their suitability for climate research. The assessment utilized expert judgment on the quality of each station. Through this process, the authors have identified a set of stations believed to be suitable for analysis of trends. Since the 1920s, snowfall has been declining in the West and the mid-Atlantic coast. In some places during recent years the decline has been more precipitous, strongly trending downward along the southern margins of the seasonal snow region, the southern Missouri River basin, and parts of the Northeast. Snowfall has been increasing since the 1920s in the lee of the Rocky Mountains, the Great Lakesnorthern Ohio Valley, and parts of the north-central United States. These areas that are in opposition to the overall pattern of declining snowfall seem to be associated with specific dynamical processes, such as upslope snow and lake-effect snow that may be responding to changes in atmospheric circulation.
\end{abstract}

\section{Introduction}

Snow plays a critical role in the climate system by substantially increasing the surface albedo when the ground is snow covered. In addition, snow is likely to be an early indicator of climate change in the cold season. Temporal variability in snow properties reflects fluctuations in both precipitation and temperature, sometimes with great sensitivity, and thus can add interpretive information about those elements. Snow on the ground and snowfall have a variety of significant socioeconomic impacts, both positive and negative. Snow is an

Corresponding author address: Kenneth E. Kunkel, Illinois State Water Survey, 2204 Griffith Dr., Champaign, IL 61820-7495. E-mail:kkunkel@uiuc.edu important component of annual runoff, recharge, and water supplies, and greatly affects water management in the northern and western United States. Rapid melt of the snowpack is a major cause of floods in the northern United States (Todhunter 2001; Graybeal and Leathers 2006). Recent studies have examined longterm historical variability in snow cover (Hughes and Robinson 1996; Frei et al. 1999). However, studies of trends in other aspects of snow climatology, such as snowfall and snow depth, have generally examined the latter half of the twentieth century because digital data prior to that time have heretofore been sparse. A study by Norton and Bolsenga (1993) identified a substantial upward trend in lake-effect snowfall near the Great Lakes from 1951 to 1980. Burnett et al. (2003) found that trends at several stations in the lake-effect snow- 
belts in the Great Lakes basin continued upward until the end of the century. Groisman et al. (2004) found a decreasing trend in spring season snowfall and a general shortening of the snow season, and stated that this was likely associated with recent spring season warming. A variety of recent studies pointed to reduced snowfall leading to significant and potentially serious declines in spring snowpack in the western United States (Mote 2003; Mote et al. 2005; Hamlet et al. 2005; Regonda et al. 2005; Stewart et al. 2005; Knowles et al. 2006).

Routine keying of the data from 1948 and later from the National Weather Service's Cooperative Observer Network began in 1948. Most of the pre-1948 daily data, including snowfall, were keyed under the Climate Database Modernization Program (Kunkel et al. 2005). Kunkel et al. (2007) described a number of issues with snowfall data that potentially affect long-term trends analysis. Changes in station location, observer, and measurement practices are among the factors that can introduce temporal inhomogeneities into the data time series. To study long-term trends in snowfall, it is necessary to carefully screen the data to identify stations with suitable temporal homogeneity. This paper describes the results of just such an effort, including the procedures used and the outcomes.

\section{Methods}

The primary method for determining each station's quality was the integration of a number of independent expert assessments by a team of scientists (the authors of this paper) experienced in the use of snow data. The expert assessments [methods to discover a rational consensus on an issue; see critique by Cooke (1991)] were supported by several objective changepoint detection tests and graphical tools available on a Web site accessible to the authors.

Stations were first screened based on missing data. To be considered as a candidate, missing data days had to constitute less than $10 \%$ of the total number of days for the period 1930-2004 during the months of October through May. A refinement of this criterion was applied after it was discovered that for some stations during some periods only nonzero amounts were keyed in while the rest of the days in the month were entered as missing. This appears to represent a misinterpretation of the intent of the observer, who in many cases leaves the snowfall column blank when a zero value is implied; therefore, when a month of data for a specific station included nonzero snowfall values, while all other days were entered as missing, these missing values were re- placed with zeroes when one or more of the following criteria were met: 1) total precipitation was entered as zero, or 2) precipitation was nonzero, but the minimum temperature was greater than $32^{\circ} \mathrm{F}$. A second sweep of the data was made to eliminate those snow seasons from which an entire month or more of observations was missing in the heart of the season (December, January, and February).

As an extra quality control of the snowfall data, the standardized anomaly (departure from average divided by standard deviation) was calculated for the snow season at each station. For seasons that had standardized anomalies greater than 5.0 or less than -5.0 , the season's data were checked against the observer forms, Climatological Data publications, or surrounding station data. When inconsistencies were found between our database and those records on the published forms, the database was corrected. Some errors included the recording of snow depth as snowfall, values being recorded as a multiple of 10 higher than they were, and other simple typos.

Given the length of the time series, it was possible for some stations to meet the $10 \%$ criteria and have their missing periods clustered at the beginning or end of time windows being used to calculate trends. Standard least squares linear trend analyses used here are potentially sensitive to conditions at either end of a time series. Therefore, stations were required to have at least five valid snow season totals during the first decade and last decade of any trend analysis to ensure that the trend was truly representative of the period in question.

A further screening criterion required that the 193738 to 2006-07 long-term mean snowfall be in excess of $12.5 \mathrm{~cm}$. This is a somewhat arbitrary cutoff, but serves the main purpose of eliminating southern areas where snowfall is infrequent and not a central aspect of the climate. The geographic distribution of the 1124 stations meeting the data availability and mean seasonal snowfall criteria was not uniform (not shown). Station density was highest from the southern plains through the central Midwest, with substantially reduced station availability in the northern plains-intermountain region and, surprisingly, in the area from the Appalachian Mountains to the mid-Atlantic and Northeast. The distinct lack of eligible snowfall stations in the East is surprising, given the long general climate records in this region, and no obvious explanation is evident.

To support the expert quality assessment, two graphs were prepared for each targeted long-term station. One showed time series of annual snowfall for the station and the 14 nearest stations with at least $30 \mathrm{yr}$ of data. 
Annual Snow Anomaly [Anom(ref)-Anom(stn)] Red_Lodge_1_NW_MT (115 in)

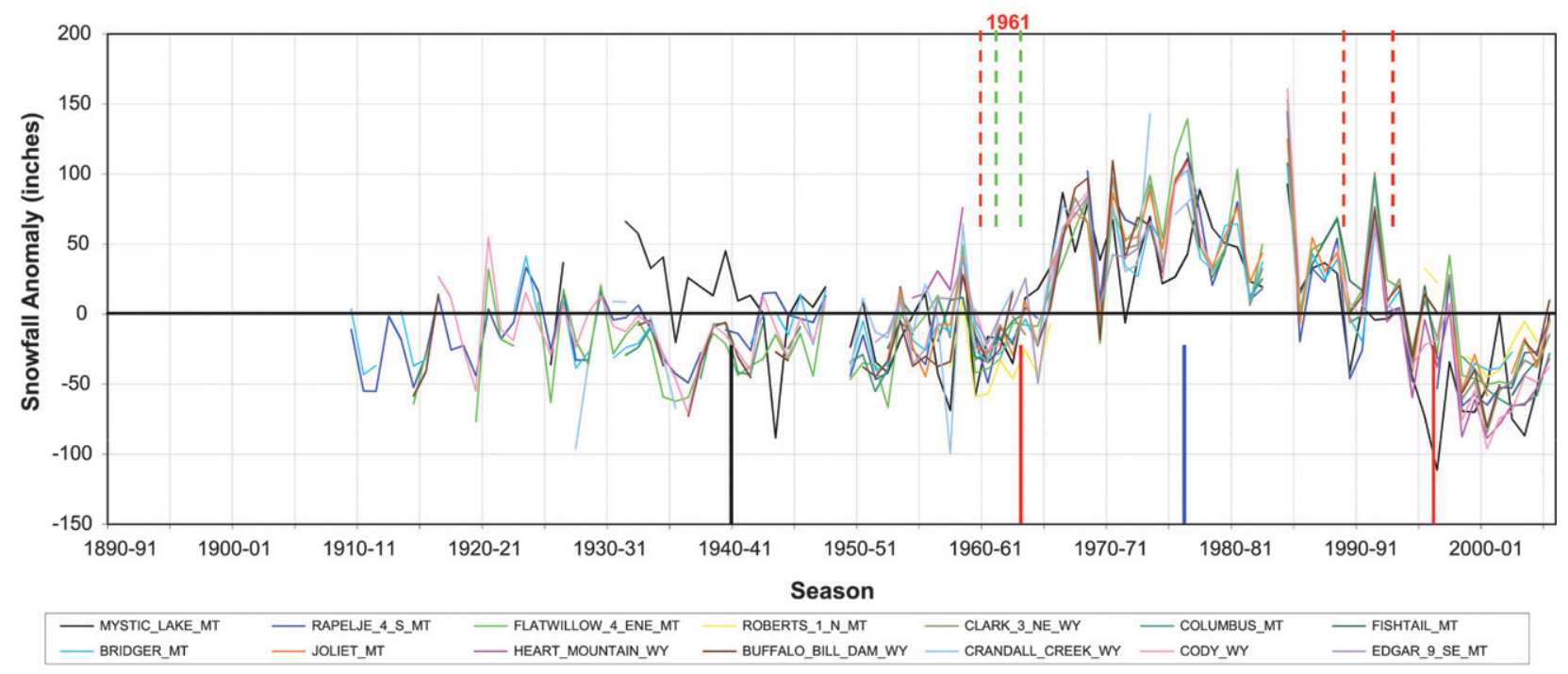

Annual Snow Anomaly [Anom(ref)-Anom(stn)] Moscow_Univ_of_Idaho_ID (49 in)

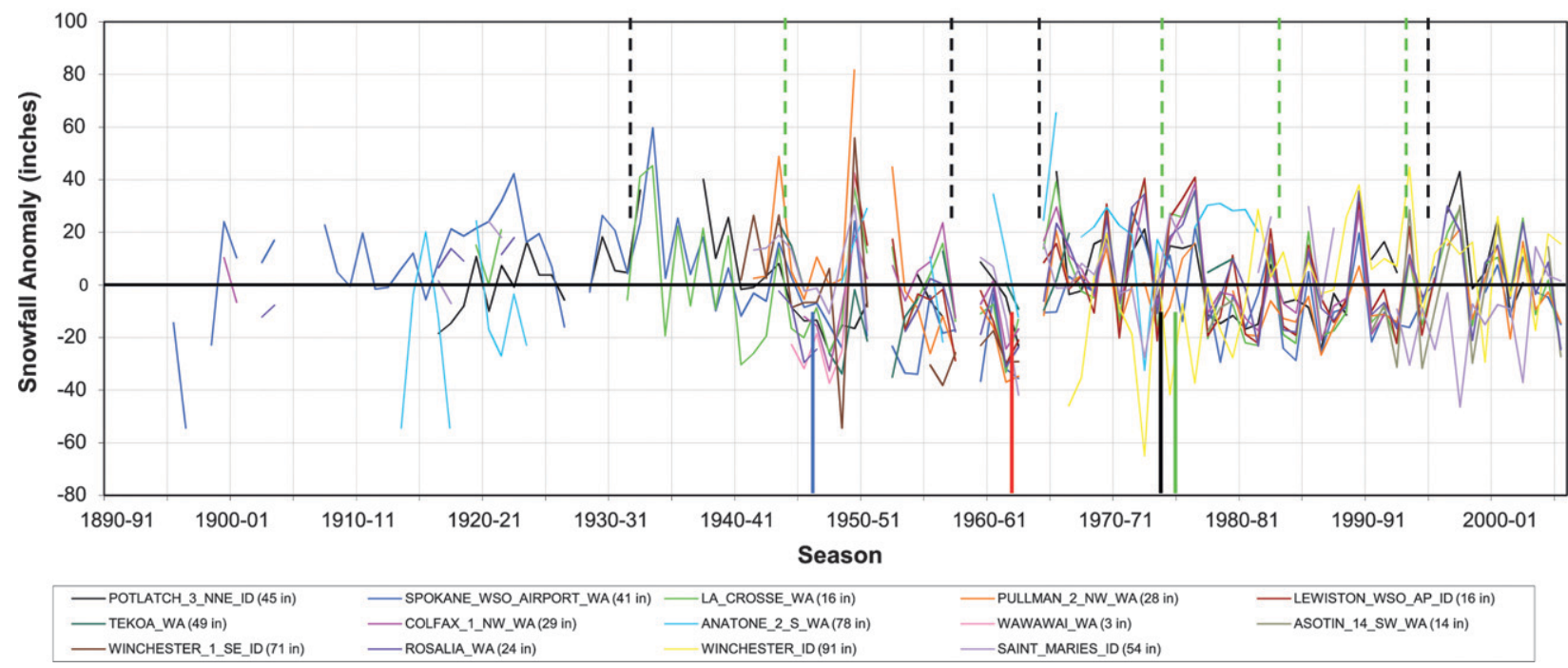

FIG. 1. Annual anomalies (in.) of the differences between the target reference station snowfall anomalies at (top) Red Lodge, MT, and (bottom) Moscow, ID, and the snowfall anomalies of the closest 14 stations with at least $30 \mathrm{yr}$ of records. Dashed vertical lines extending downward from the upper margin of the graph indicate known station or observer changes at target or comparison stations, whereas both solid vertical lines extending upward from the lower margin and years printed above the upper margin indicate discontinuities objectively identified using separate methods (see text). The changepoint indicators are color coded by station, with red assigned to the target station.

The second showed time series of the difference between the annual snowfall anomaly for the targeted station minus the annual snowfall anomaly for each of the same 14 nearest stations as shown in the annual snowfall time series graph. The times of station moves or observer changes recorded in station histories were noted on the graphs. Figure 1 displays two examples of the latter type of graph, for Red Lodge, Montana, and
Moscow, Idaho. The Red Lodge diagram illustrates the case of a strong step change in snow anomaly differences coincident with a known station change in 1961 recorded in metadata (red dashed line from top margin). Values are expressed in the original English units of measurement. The visual cue of a large deflection in snowfall anomaly differences was quite apparent, indicating that after 1961, Red Lodge recorded relatively 
greater positive snow departures from its long-term mean than did the 14 nearest stations.

A central assumption in this assessment is that multiyear fluctuations in snowfall will be spatially coherent and detectable by multiple stations; thus, the type of isolated behavior exhibited by Red Lodge is assumed to arise from factors other than climatological. In complex terrain, local climate responses to regional forcings may differ among the entire set of stations, but it is likely that a few stations in similar circumstances will respond in a similar way. In addition, in complex terrain seasonal averages can vary by an order of magnitude or more in short distances.

An objective screening technique using multiple test statistics and a composite reference time series (Menne and Williams 2005) detected the changepoint (solid red line from bottom margin). A second objective assessment was made based on first identifying homogeneous data series (Lund and Reeves 2002) and then using these stations to form a reference time series for detecting changepoints at other stations (Alexandersson and Moberg 1997). The years of any detected changes are placed outside the top margin in the evaluation graphs. For example, a changepoint was detected by this method at Red Lodge in 1961 (Fig. 1, top). The need for expert examination is apparent, however, in the Moscow diagram (Fig. 1, bottom), as the first objective test detected a changepoint in the early 1960s that was not confirmed by the second objective test nor by expert assessment. Even in this case, there remains slight ambiguity among the experts about the relative reduction from about 1978-79 to 1995-96 of perhaps $10 \%-20 \%$ with respect to surrounding station records, but not sufficient to discard the station. The record was determined to be homogeneous, with a few short data gaps likely triggering the objectively determined change detection algorithm.

The results of the two objective techniques were compared with each other and with documented station changes. More than $75 \%$ of the objectively determined changepoints were not related to any documented changes. Also, the two sets of objectively determined changepoints had only about $50 \%$ overlap. Thus, each set of changepoints represents a largely independent source of information about possible inhomogeneities. There was some geographical variation in the typical number of changepoints per station. This number tended to be higher in the central United States where the density of stations is higher. The higher number of nearby stations may enhance the ability of these objective tests to detect smaller shifts.

The principal reasons for an expert's rejection of a station as homogenous were
1) one or more large, relative to the natural spatial variations, step changes in the snowfall anomaly differences with adjacent stations, particularly if associated with documented station changes or objectively determined changepoints;

2) a substantial portion of the missing data occurring at the ends of the time series;

3) a substantial long-term trend in the snowfall anomaly differences with adjacent stations; and

4) step changes in the snowfall anomaly differences with adjacent stations across a data gap.

The results of this quality-control process and its impacts on trend estimation are discussed in section 3 .

\section{Results}

\section{a. Selection of homogeneous snow trend stations}

A total of 1124 potential long-term snow trend stations was assessed by the authors and placed into one of three categories: "homogeneous" (suitable for trends analysis), "inhomogeneous" (not suitable for trends analysis), and "questionable" (the time series exhibited some questionable behavior but may be suitable for some purposes, such as filling in an area with no other stations). Less than $50 \%$ of the stations, 440 , were judged by a plurality of experts to be homogeneous. As noted above, years where at least one of the core winter snow season months was missing were considered missing for seasonal snowfall totals used in trends analyses. Combined with the requirement that a station have at least $5 \mathrm{yr}$ of data in the beginning and ending decades of a trend analysis, the numbers of stations available was reduced further with time: 419 stations for 1930-31 to 2006-07, 322 stations for 1920-21 to 2006-07, 267 stations for 1910-11 to 2006-07, and 199 stations for 1900 01 to 2006-07. For the most part, stations used to calculate trends for the longer periods are also available for shorter periods, although some exceptions do occur when a longer station record has a data gap in the 1910s, 1920s, or 1930s and cannot be used to calculate a trend starting in those decades. The distribution of homogeneous stations is quite dense along the southern margins of the seasonal snow region in the central United States (Fig. 2), but becomes more sparse in the western and northern United States and in the eastern United States, especially for periods beginning prior to 1930. The geographic pattern of relative abundance of homogenous stations is quite similar to that of the 1124 stations with sufficient data available to be included in this analysis (not shown).

In evaluating the snow station records, the panel of seven experts had some internal variation in their over- 


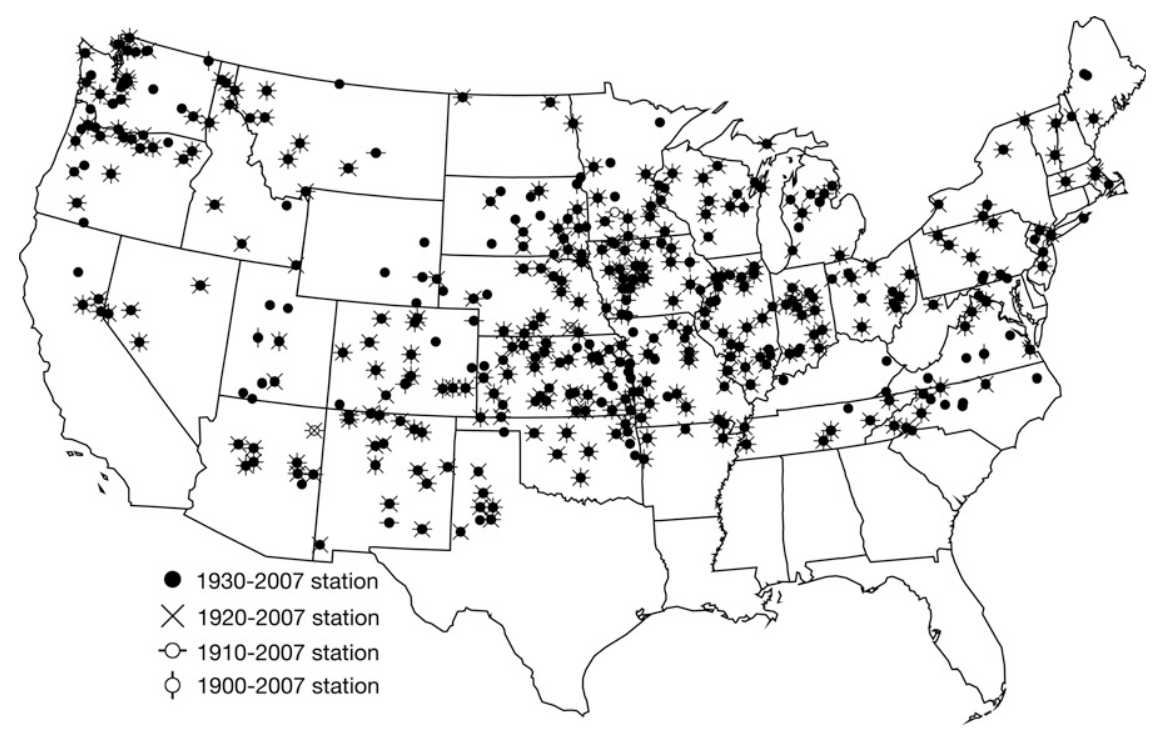

FIG. 2. Homogeneous snowfall stations selected by a plurality of evaluators, with fewer than $5 \mathrm{yr}$ missing in each of the beginning decades and in the ending decade for trend analyses. The symbols overlap at the locations of stations available for multiple trend periods.

all demarcation of stations into the homogeneous, inhomogeneous, and questionable categories. Evaluators 1,4 , and 7 designated $10 \%-20 \%$ more of the stations as homogeneous than did the other evaluators; evaluators 1 and 7 displayed a concomitant reduction in inhomogeneous designations, while evaluator 4 had the lowest percentage of questionable stations (Fig. 3). Evaluator 2 tended to designate more stations as inhomogeneous than did anyone else. The other evaluators were fairly close to the middle of the distribution. These differences in judgment reflect the varying backgrounds and experiences of the authors, and also any biases related to their geographical location and local knowledge of snow data properties in their regions. The voting approach used here in designating snow station homogeneity incorporates many nuances that objective quantitative measures may lack, while guarding against the domination of one idiosyncratic viewpoint regarding what constitutes homogeneity.

One way to demonstrate the efficacy of the team approach to homogeneity determination is to see how well long-term trends in snowfall agree between stations designated unanimously or nearly unanimously as homogeneous and stations over which there was some level of disagreement. Comparing U.S. snowfall trends for the period 1930-31 to 2006-07 (Fig. 4), the pattern derived from stations with unanimous or nearly unanimous homogeneous designations (Fig. 4a) is similar to the pattern for stations where only three, four, or five out of seven evaluators agreed (Fig. 4b). The trends are given as the percentage change of snowfall per year relative to the long-term $1937-38$ to $2006-07$ mean. Snowfall declined over much of the nation during this period, with the largest rates of reduction in the Pacific Northwest, the Southwest, a region centered on eastern Kansas and Missouri, and across several mid-Atlantic states. Annual snowfall decreased over these $78 \mathrm{yr}$ at a slower rate elsewhere in the country, except in the lee of the Rocky Mountains and in the Great Lakes area, where snowfall increased. There are some differences between the two patterns, but these are largely explained by the lack of station availability in the intermountain region, the northern Great Plains, and the southernmost extent of the spatial distribution, where few stations are available in either homogeneity class.

More detailed examinations of the 1930-31 to 2006-

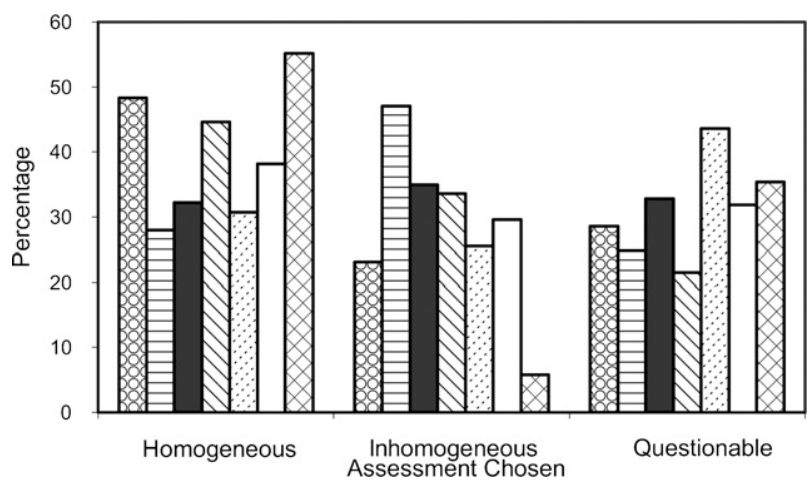

FIG. 3. The percentages of stations assigned to homogeneous, inhomogeneous, and questionable categories by each of the seven evaluators. A separate pattern is used for each evaluator. 

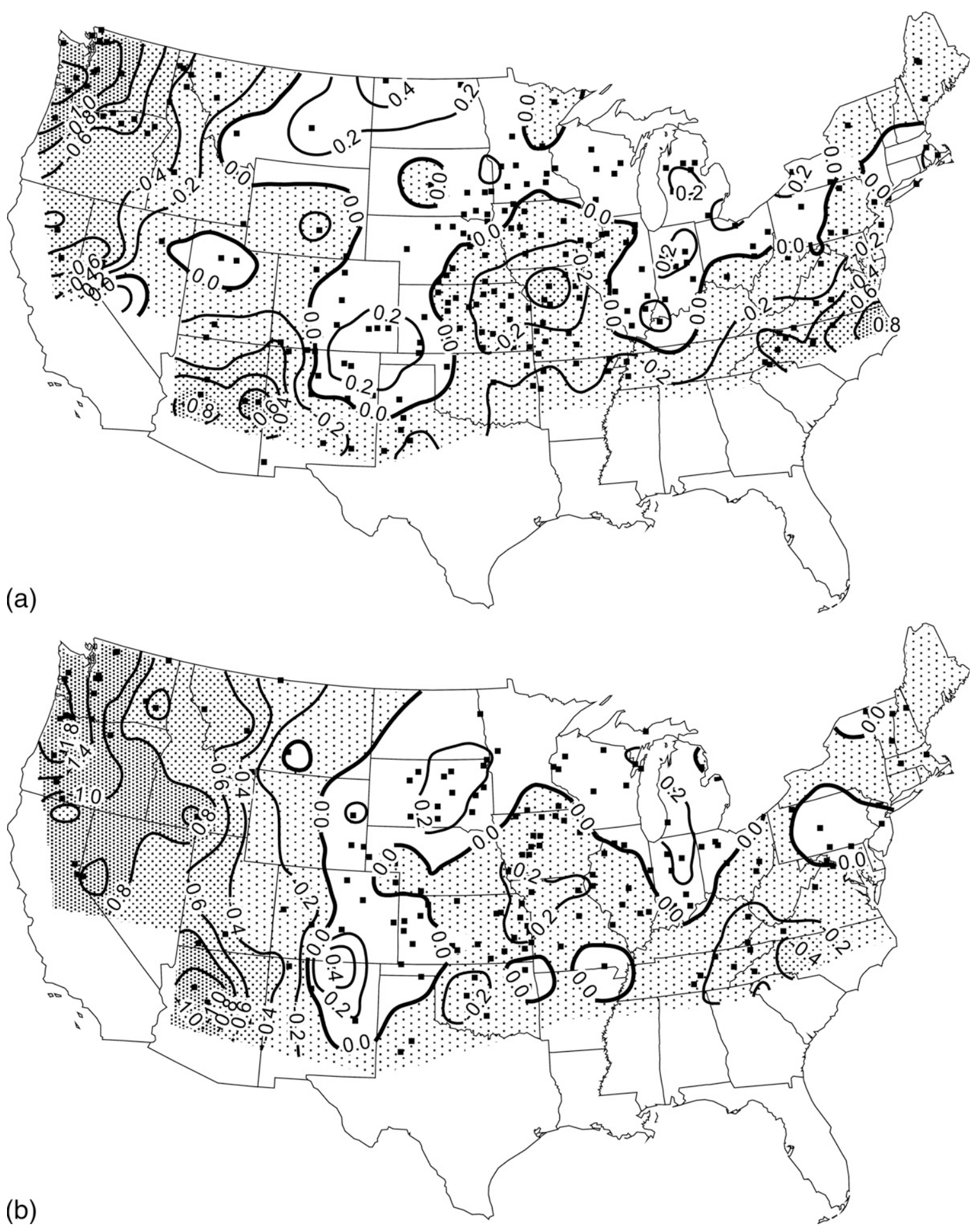

FIG. 4. Snowfall trend maps for 1930-31 to 2006-07 derived from stations judged to be homogenous by (a) all or all but one evaluator; (b) 3, 4, or 5 evaluators; and (c) individual stations from (a) and (b). Trends are given as a percentage of the 1937-38 to 2006-07 snowfall mean per year. Closed circles: positive trends; open circles and stippling: negative trends. 


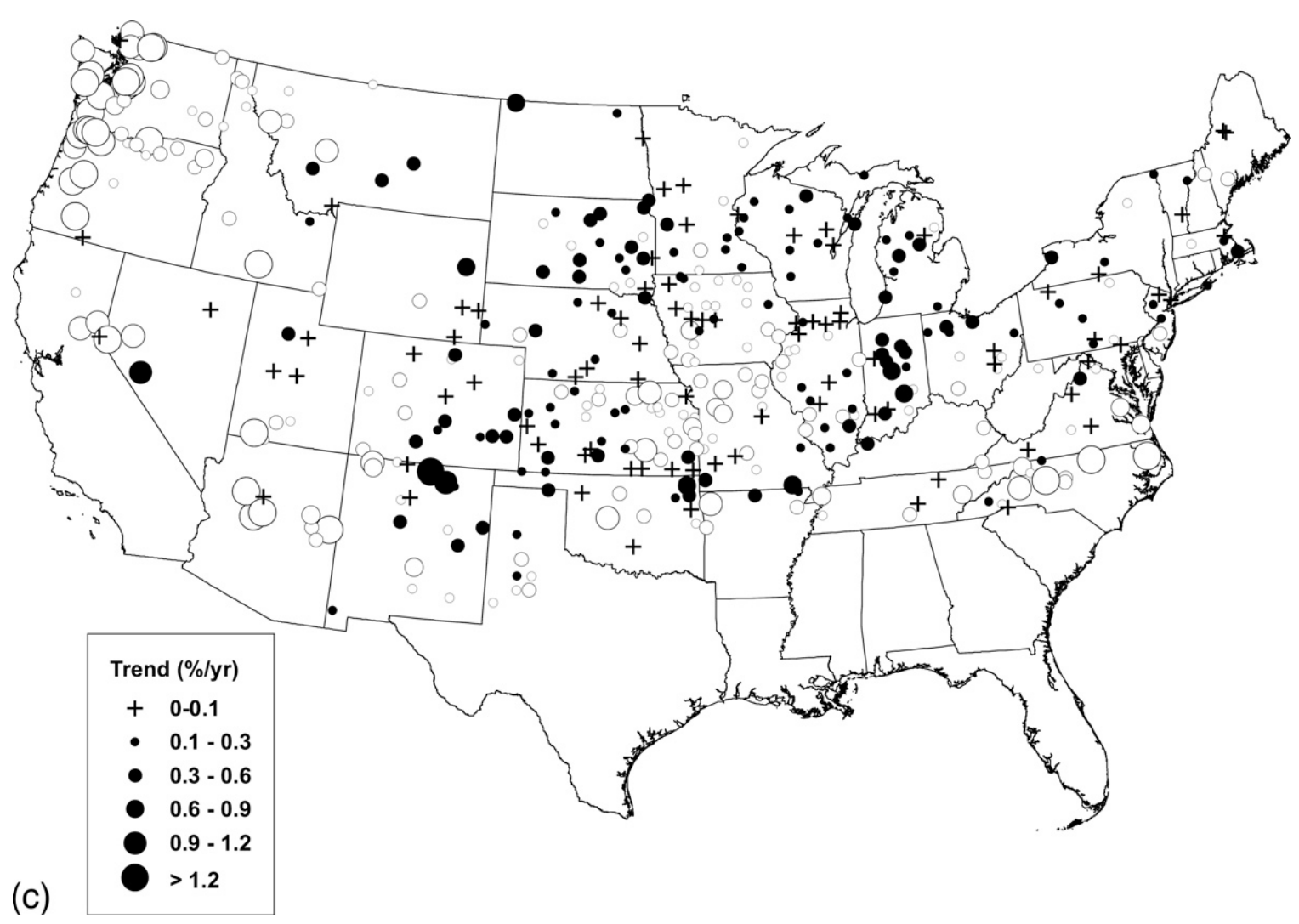

FIG. 4. (Continued)

07 snowfall trends of all 419 stations accepted as homogeneous (Fig. 4c) clearly reveal that the large-amplitude features seen on the contour maps are driven by the agreement among many stations in these regions trending in the same direction. The Northwest, Southwest, mid-Atlantic, and Kansas-Missouri largeamplitude trend areas are consistently negative, while the large-amplitude trend areas in the lee of the Rocky Mountains and in the Great Lakes-upper Ohio Valley areas are consistently positive. Other features also seen on the contour maps include a consistent downward trend in snowfall at the southern margin of the seasonal snow cover from Arizona to North Carolina, and a small but generally positive trend in snowfall in the central-northern United States.

The evaluation of trends derived from these carefully selected homogenous snowfall records shows them to be consistent geographically, although the coverage is sparse in some areas. The selection methodology appears to be quite robust, using multiple evaluators to overcome the vagaries of individual subjectivity. Therefore, it is reasonable to proceed to an analysis that more fully characterizes the long-term trends of snowfall in the United States.

\section{b. Evaluation of U.S. snowfall trends over long time periods}

Snowfall trends have been examined recently in regional contexts, such as in studies of Great Lakes lakeeffect snowfall (Burnett et al. 2003; Ellis and Johnson 2004), New England snowfall (Huntington et al. 2004), and as part of larger studies of the fate of the western snowpack (Mote 2003; Mote et al. 2005; Regonda et al. 2005). All of these studies support the findings for snowfall trends in the 1930-31 to 2006-07 period determined in this work, namely, steep downward trends in the far West, upward trends in the Great Lakes, and mildly downward trends in New England (Fig. 5a). The most recent studies of U.S. national annual snowfall trends were completed in the 1990s (Leathers et al. 1993; Karl et al. 1993; Groisman and Easterling 1994), although spring snowfall has been the subject of more attention recently (Groisman et al. 2004). Unfortunately, the national annual snowfall studies mentioned cannot be directly compared to this study, given differing starting and ending times for the periods of interest, or focus on one part of the season. The study by Knowles et al. (2006) does map trends to the current 

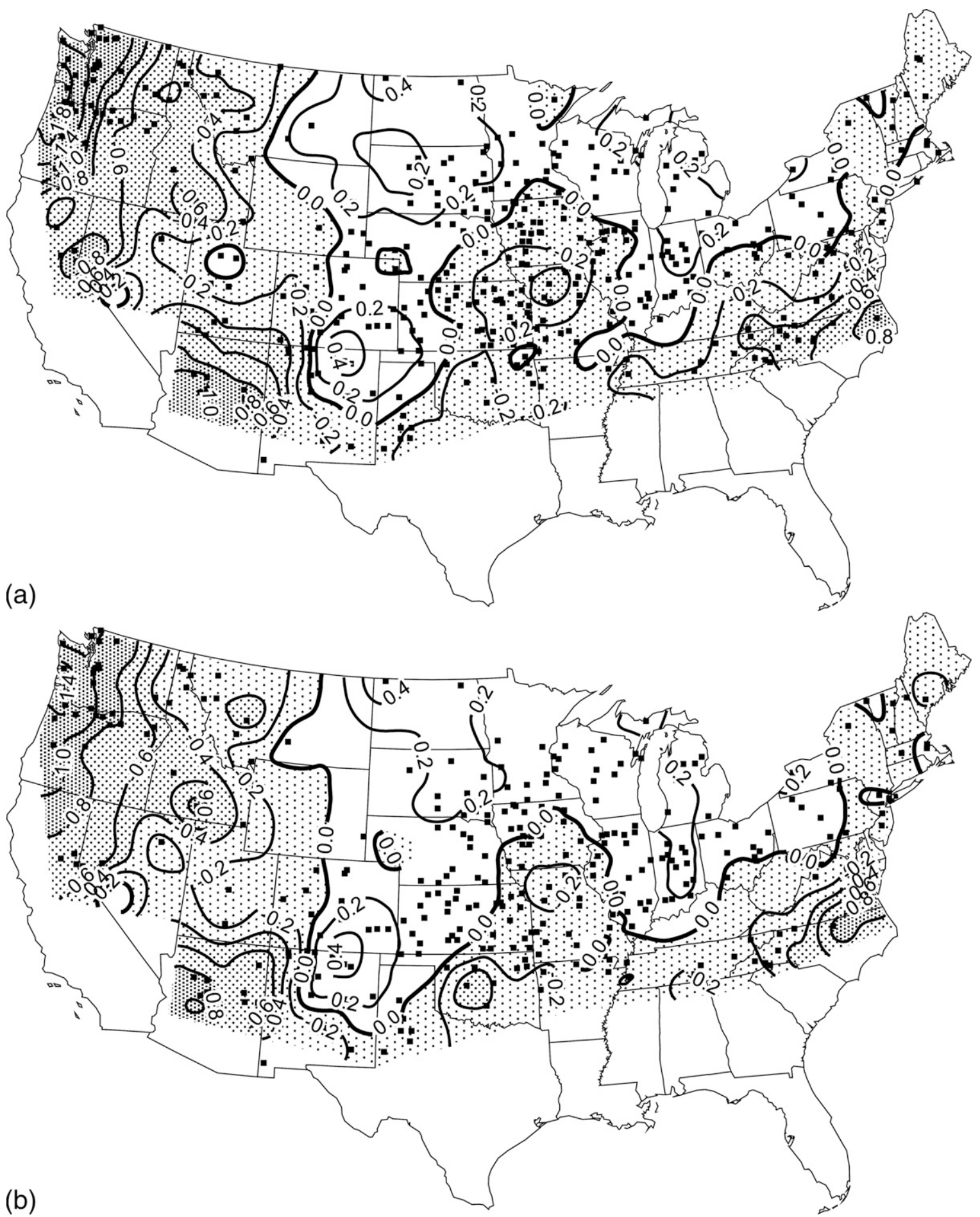

FIG. 5. Snowfall trend maps derived from stations judged to be homogenous by a plurality of the evaluators: (a) 1930-31 to 2006-07, (b) 1920-21 to 2006-07, (c) 1910-11 to 2006-07, and (d) 1900-01 to 2006-07. Trends are given as a percentage of the 1937-38 to 2006-07 snowfall mean per year. Stippling indicates negative trends.

decade in the water equivalent of snowfall in the western United States, with their Fig. 3 indicating substantial downward trends in the water equivalent of snowfall in western mountain ranges, but with some in- creases in the area east of the Rocky Mountains as seen in this study.

Annual snowfall generally exhibits greater variability than other elements typically examined for climatic 

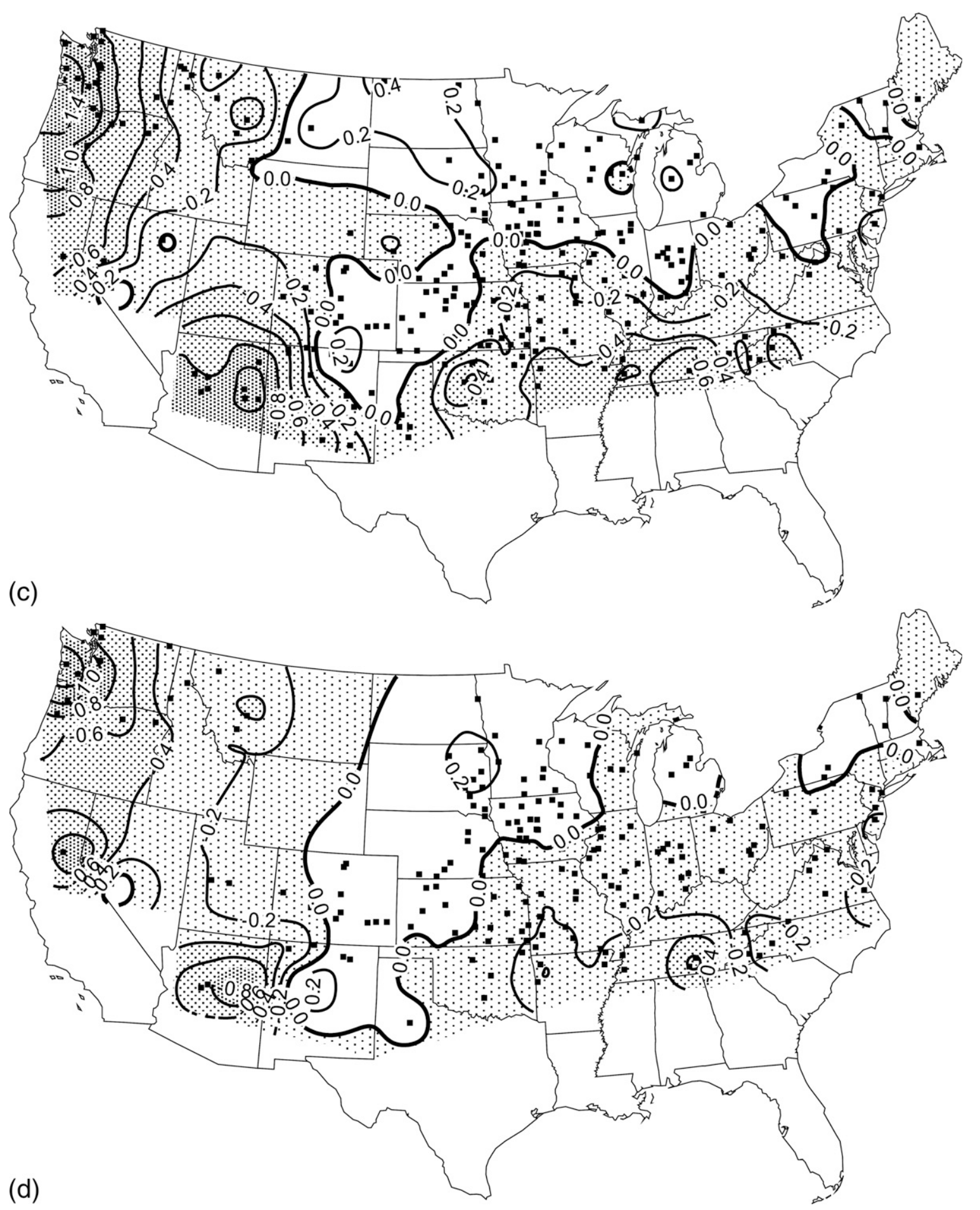

FIG. 5. (Continued)

trends. The coefficient of variation ranges from around 0.3 to greater than 1.0. There are substantial spatial variations (not shown). The lowest values are found in the north-central and northeastern United States, indicating the relative consistency of snowfall from year to year. Much higher values are found along the southern fringes of the typically snowy areas and along the northwest coast. Trends in these latter areas will be associated with higher uncertainties.

The 1930-31 to 2006-07 snow season total trends 
mapped from all 419 eligible homogenous stations (Fig. 5a) reveal an interesting pattern of change, despite data sparsity in some areas. The western rates of decline relative to the long-term mean are large, with a cluster of stations in the far Northwest exceeding rates of $1 \%$ $\mathrm{yr}^{-1}$. In other words, snow season snowfall totals have fallen to less than half of their former value at these stations. Steep declines in snowfall totals are also seen in the Southwest, indicating the impacts of spring warming and the conversion of spring season snowfall to liquid precipitation. Snowfall amounts are declining along the southern margins of the seasonal snowpack in the United States, with especially pronounced downward trends in the mid-Atlantic states. Snowfall declines are weaker but still present along the New Jersey coast and northward into northern New England. Finally, there is a large region of moderate rates of snowfall decline in the central United States around northern Missouri and eastern Kansas.

Snowfall increases in the $1930-31$ to $2006-07$ period are concentrated in three areas. The largest percentage increases in snowfall are located in the lee of the Rocky Mountains, especially in New Mexico and Colorado, in the Great Lakes-northern Ohio Valley region, and in the northern tier of the United States. While the snowfall trend in the northern plains is somewhat weak, it was also seen in the study by Leathers et al. (1993). Interestingly, snowfall increases in the two main regions noted appear to be related to synoptic-dynamical trends in the atmospheric circulation. Grover and Sousounis (2002) and Ellis and Johnson (2004) have already identified circulation changes that have been responsible for some upward trends in lake-effect snowfall, in conjunction with a longer open ice season. These trends are not seen as strongly in this study, as some of the long-term snowfall stations in the Great Lakes lakeeffect belts were either too short for this study or were determined to be inhomogeneous. The possibility remains that strong local variations in snow forcing, associated with Great Lakes flow patterns, could produce legitimate large local variation in snow histories. Though beyond the scope of the present study, this deserves a closer analysis. The locations in New Mexico and Colorado with increasing snowfall may be experiencing an increase in the frequency of upslope events and/or the availability of moisture during the winter. Warming temperatures in this region that would otherwise curtail seasonal snowfall totals during spring would also allow more moisture to be involved with midwinter upslope snow events that were moisture starved in colder conditions. More generally, the meteorological, geographic, and topographic factors that contribute to total seasonal snowfall at individual loca- tions can vary somewhat independently, and by month or season, and it is thus not clear how coherently snowfall records should be expected to resemble each other on the basis of theoretical considerations, even given perfect observations. Furthermore, snow occurrence and amount are affected by both temperature and precipitation, sometimes delicately intertwined, and significant nonlinearities are possible.

As the start date for trends moves back to the 1920 21 snow season (Fig. 5b), the number of homogeneous snowfall stations drops to 322 . However, the general distribution of stations is sufficient to confirm the existence of a similar pattern of snowfall trends over the United States as was seen from 1930-31 onward. Snowfall has declined since 1920-21 in the West, southern snowpack edge, East Coast, and central U.S. regions, and increased in the upslope regions in the lee of the Rockies and in the Great Lakes-northern Ohio Valley region. A subtle change occurred in the data-rich area of the central Great Plains, where the edge of the zerosnowfall trend line contracted somewhat toward northern Missouri. Overall though, the map of the 1920-21 to 2006-07 trends reinforces the general findings of the 1930-31 to 2006-07 analysis without being burdened with the complication of starting in an era of widespread drought. Therefore, these findings confirm the previous findings that snowfall trends over the United States are predominantly negative except for some regions that have been impacted more strongly by changes in atmospheric circulation characteristics.

Maps of snowfall trends starting in 1910-11 (Fig. 5c) and 1900-01 (Fig. 5d) are more substantially impacted by the drop-off in the availability of quality stations. Despite these limitations, there is a general impression of more of the United States being impacted by snowfall declines even over these longer periods. The southern edge of the seasonal snow region in the United States seems to have the largest downward snowfall trends in the central and eastern United States at these time scales, although much of the north-central United States and Great Plains still indicates increasing snowfall trends as seen in the 1920-21 to 2006-07 or 1930-31 to 2006-07 maps. The fact that the 1910-11 to 2006-07 trend map still retains many of the features of the maps of trends starting later indicates the importance of changes in the latter portion of the time series in determining the overall snowfall trends over the last $100 \mathrm{yr}$.

\section{Summary and conclusions}

From a climate system standpoint, snow cover is responsible for a critical feedback process in the global 
energy balance (Hughes and Robinson 1996; Frei et al. 1999), and snow depth/snow water equivalent is a key variable for surface hydrology (Mote 2003; Dyer and Mote 2006). Unfortunately, snowfall is difficult to measure accurately and consistently over time (Doesken and Judson 1997). It is also possible that trends in snow cover at the start or end of the snow accumulation and melt seasons may affect temperature trends or atmospheric circulation patterns as feedback mechanisms (Abatzoglou and Redmond 2007). Despite these considerations, snowfall is of primary consequence, as it is the process through which the snow cover and the snow water equivalent of the snowpack are laid down and replenished. Therefore, it is important to monitor trends in snowfall as assiduously as the other measures of the climate state.

This study has endeavored to improve our knowledge of snowfall trends in the United States by identifying stations that have long-term homogenous time series. After a series of objective quality criteria were applied, a group of seven evaluators utilized time series visualization tools to subjectively examine more than 1100 stations that met initial quality requirements. Only 440 were found to be homogeneous by a plurality of evaluators. This number was further reduced by considerations related to missing data at the beginning and ending of time series. Snow is notoriously difficult to measure accurately and consistently (Doesken and Judson 1997). Thus, it is perhaps no surprise that few of the approximately 8000 stations recording hydrologic data have snowfall records of the requisite quality, but the number of quality stations appears to be sufficient to capture the patterns of trends. The stations with long homogenous snow records should be given priority for preservation into the future. The subset of snowfall records used for analysis in this study can be obtained from the Midwestern Regional Climate Center (http:// mrcc.isws.illinois.edu/) or from the National Climatic Data Center (NCDC).

The final set of stations was found to have highly consistent snowfall trends in the various regions of the United States, although some areas of the intermountain west and the north-central United States ended up with quite low station densities not fully representative of their potential complexities. Unfortunately, these also happen to be where spatial differences in snowfall are extremely large, and where snowfall and snow water content are vital to annual streamflow, human consumption, and ecological function. Since the 1920s, snowfall has been declining precipitously in the West and the mid-Atlantic coast, and is strongly trending downward along the southern margins of the seasonal snow region, the southern Missouri River basin, and parts of the Northeast. Snowfall has been increasing since the 1920s in the lee of the Rocky Mountains, the Great Lakes-northern Ohio Valley, and parts of the north-central United States. These areas that are trending in opposition to the overall pattern of declining snowfall seem to be associated with specific dynamical processes such as upslope snow and lake-effect snow that may be responding to changes in large-scale atmospheric circulation patterns.

Acknowledgments. This work was partially supported by National Oceanic and Atmospheric Administration Office of Global Program Award NA05OAR4310016. Additional support was provided by NOAA Cooperative Agreement NA17RJ1222. Any opinions, findings, and conclusions are those of the authors and do not necessarily reflect the views of NOAA or the institutions for which they work.

\section{REFERENCES}

Abatzoglou, J. T., and K. T. Redmond, 2007: Asymmetry between trends in spring and autumn temperature and circulation regimes over western North America. Geophys. Res. Lett., 34, L18808, doi:10.1029/2007GL030891.

Alexandersson, H., and A. Moberg, 1997: Homogenization of Swedish temperature data. Part I: Homogeneity test for linear trends. Int. J. Climatol., 17, 25-34.

Burnett, A. W., M. E. Kirby, H. T. Mullins, and W. P. Patterson, 2003: Increasing Great Lake-effect snowfall during the twentieth century: A regional response to global warming? J. Climate, 16, 3535-3541.

Cooke, R. M., 1991: Experts in Uncertainty: Opinion and Subjective Probability in Science. Oxford University Press, 336 pp.

Doesken, N. J., and A. Judson, 1997: The Snow Booklet: A Guide to the Science, Climatology, and Measurement of Snow in the United States. Colorado Climate Center, $86 \mathrm{pp}$.

Dyer, J. L., and T. L. Mote, 2006: Spatial variability and trends in observed snow depth over North America. Geophys. Res. Lett., 33, L16503, doi:10.1029/2006GL027258.

Ellis, A. W., and J. J. Johnson, 2004: Hydroclimatic analysis of snowfall trends associated with the North American Great Lakes. J. Hydrometeor., 5, 471-486.

Frei, A., D. A. Robinson, and M. G. Hughes, 1999: North American snow extent: 1900-1994. Int. J. Climatol., 19, 1517-1534.

Graybeal, D. Y., and D. J. Leathers, 2006: Snowmelt-related flood risk in Appalachia: First estimates from a historical snow climatology. J. Appl. Meteor. Climatol., 45, 178-193.

Groisman, P. Ya., and D. R. Easterling, 1994: Variability and trends of total precipitation and snowfall over the United States and Canada. J. Climate, 7, 184-205.

, R. W. Knight, T. R. Karl, D. R. Easterling, B. Sun, and J. H. Lawrimore, 2004: Contemporary changes of the hydrological cycle over the contiguous United States: Trends derived from in situ observations. J. Hydrometeor., 5, 64-85.

Grover, E. K., and P. J. Sousounis, 2002: The influence of largescale flow on fall precipitation systems in the Great Lakes basin. J. Climate, 15, 1943-1956.

Hamlet, A. F., P. W. Mote, M. P. Clark, and D. P. Lettenmeier, 2005: Effects of temperature and precipitation trends on 
snowpack in the western United States. J. Climate, 18, 45454561.

Hughes, M. G., and D. A. Robinson, 1996: Historical snow cover variability in the Great Plains region of the USA: 1910 through to 1993. Int. J. Climatol., 16, 1005-1018.

Huntington, T. G., G. A. Hodgkins, B. D. Keim, and R. W. Dudley, 2004: Changes in the proportion of precipitation occurring as snow in New England (1949-2000). J. Climate, 17, 2626-2636.

Karl, T. R., P. Ya. Groisman, R. W. Knight, and R. R. Heim, 1993: Recent variations in snow cover and snowfall in North America and their relation to precipitation and temperature variations. J. Climate, 6, 1327-1344.

Knowles, N., M. D. Dettinger, and D. R. Cayan, 2006: Trends in snowfall versus rainfall in the western United States. J. Climate, 19, 4545-4559.

Kunkel, K. E., D. R. Easterling, K. Hubbard, K. Redmond, K. Andsager, M. Kruk, and M. Spinar, 2005: Quality control of pre-1948 cooperative observer network data. J. Atmos. Oceanic Technol., 22, 1691-1705.

—, M. Palecki, K. G. Hubbard, D. Robinson, K. Redmond, and D. Easterling, 2007: Trend identification in 20th century U.S. snowfall: The challenges. J. Atmos. Oceanic Technol., 24, 64 73.

Leathers, D. J., T. L. Mote, K. C. Kuivinen, S. McFeeters, and D. R. Kluck, 1993: Temporal characteristics of USA snowfall
1945-1946 through to 1984-1985. Int. J. Climatol., 13, 65 76.

Lund, R., and J. Reeves, 2002: Detection of undocumented change points-A revision of the two-phase model. J. Climate, 15, 2547-2554.

Menne, M. J., and C. N. Williams, 2005: Detection of changepoints using multiple test statistics and composite reference series. J. Climate, 18, 4271-4286.

Mote, P. W., 2003: Trends in snow water equivalent in the Pacific Northwest and their climatic causes. Geophys. Res. Lett., 30, 1601, doi:10.1029/2003GL017258.

— A. F. Hamlet, M. P. Clark, and D. P. Lettenmaier, 2005: Declining mountain snowpack in western North America. Bull. Amer. Meteor. Soc., 86, 39-49.

Norton, D. C., and S. J. Bolsenga, 1993: Spatiotemporal trends in lake effect and continental snowfall in the Laurentian Great Lakes, 1951-1980. J. Climate, 6, 1943-1956.

Regonda, S. K., B. Rajagapalan, M. Clark, and J. Pitlick, 2005: Seasonal cycle shifts in hydroclimatology over the western United States. J. Climate, 18, 372-384.

Stewart, I. T., D. R. Cayan, and M. D. Dettinger, 2005: Changes toward earlier streamflow timing across western North America. J. Climate, 18, 1136-1155.

Todhunter, P. E., 2001: A hydroclimatological analysis of the Red River of the North snowmelt flood catastrophe of 1997. J. Amer. Water Resour. Assoc., 37, 1263-1278. 